\title{
Pela 'Luz' dos nossos olhos: uma interpretação do bairro paulistano
}

\author{
For the 'Luz' of our eyes: an interpretation \\ of the Luz Quarter of São Paulo
}

\author{
Maria Cristina da Silva Schicchi \\ Programa de Pós-graduação em Urbanismo - PUC-Campinas \\ schicchi@ terra.com.br
}

\begin{abstract}
Resumo:
São Paulo possui bairros típicos e tradicionais que já mereceram inúmeros trabalhos monográficos. São documentos que consolidam a memória da cidade paulistana, de seus habitantes, cuja história continua sendo escrita pelo cotidiano das pessoas que habitam estes territórios. Porém, o que ressalta quando percorremos as ruas dos bairros da cidade é a herança presente de certo caráter próprio, que ao mesmo tempo em que permite a identificação de seus limites, também reforça fronteiras em relaçáo a outros bairros. Este texto trata da dificuldade de integraçáo do bairro da Luz com o contexto do centro de Sáo Paulo que lhe faz divisa. É a tentativa de interpretar alguns fatores que tornam complexa qualquer leitura sobre o bairro, e por extensão, de qualquer intervenção de reabilitação ou renovação, e uma reflexáo sobre a reiteração de seu caráter de área periférica ao centro, decorrente de sucessivas intervençôes e atividades ali localizadas historicamente.
\end{abstract}

Palavras-chave: Luz; Bairros paulistanos; Reabilitação; Usos; Urbanismo.

\begin{abstract}
:
São Paulo has typical and traditional quarters that inspired a large bibliography. These are documents that consolidate a memory of the city, of its inhabitants, whose stories is still being written by the daily life of the people that live in this territory. However, what shows when we go through the streets of the city quarters is the present heritage of a proper character that, while allowing the identification of its limits, also reinforce borders relative to other quarters. This text deals with the difficulty of integrating the Luz quarter with the context of São Paulo downtown, that borders it. It seeks the interpretation of some factors that render complex any reading of the quarter and consequently of any rehabilitation or renovation intervention and a reflection on the character of a periphery to the center area resulting from successive interventions and activities historically located there.
\end{abstract}

Keywords: Downtown; Luz; São Paulo quarters; Rehabilitation; Uses; Urbanism. 
1 - Em "A falta de pedra prejudica as construções". (BRUNO, 1981: 82)

2 - No Centro de Preservação Cultural da USP (CPC USP), de 23 de março a 29 de abril de 2011, cujos curadores foram Eduardo Costa e André Kobashi. Desta mesa específica, intitulada "Política e Memória da Cidade" participaram, além de mim, Maria Stella Bresciani e Cibeli Rizek.
A cidade de São Paulo, situada em uma chapada, ramifica-se na planície, estendendo como longos braços belos e extensos bairros que hão de, pelo futuro, chamar a si toda a importância e vitalidade... Tempo virá em que o São Paulo de hoje há de ser a cidade velha, abandonada, desprezada, posta à margem e o ex-bairro da Luz, centro de tudo que dá vida e animação. [1] Visconde de Taunay (1865)

$\mathcal{E}$ Th recente participação em uma mesa de debate ocorrida em São Paulo, como parte das atividades propostas junto à exposição de fotos "Bairro da Luz - Documentos Recentes", [2] um aspecto importante permeou as diferentes apresentaçóes e as intervençóes que se seguiram: a qual Luz nos referimos ao pretendermos discutir o seu desígnio? Ao bairro, composto pela diversidade funcional e social que incorporou transformações, porém manteve o caráter de heterogeneidade em seu desenho? À área à qual se atribui a vocação de pólo cultural, objeto dos investimentos públicos mais recentes como as reabilitaçôes da Sala São Paulo, Museu da Língua Portuguesa e Pinacoteca do Estado? À área que se constituiu historicamente e permaneceu até os anos 1960 como limite extremo da "zona de transição do centro”. (MÜLLER, 1958: 175) cindida pelos trilhos da ferrovia, permitindo todo o tipo de localização "naturalmente" inadequada à própria área central? Ou à área ocupada por diversos grupos sociais, moradores informais, habitantes do espaço público, estigmatizados e, portanto, náo computáveis nos projetos?

As fotos expostas revelavam momentos particulares vividos pelas pessoas que habitavam as edificaçóes demolidas recentemente, assim como de trabalhadores que participaram das demoliçóes, registrando a perplexidade ou indiferença dos transeuntes, moradores e comerciantes que continuam fazendo parte do cotidiano deste território.

O período documentado é o primeiro registro das ações de demolição / Ver Fig. 1] deflagradas neste ano, porém, o processo foi iniciado em 2004, quando foi criado o Projeto Nova Luz pela Prefeitura de São Paulo, que prevê a intervenção em uma área correspondente a 23 quadras, em que metade - cerca de 10 quadras, 105 mil m² ou 750 imóveis - foram declaradas de utilidade pública pela prefeitu-

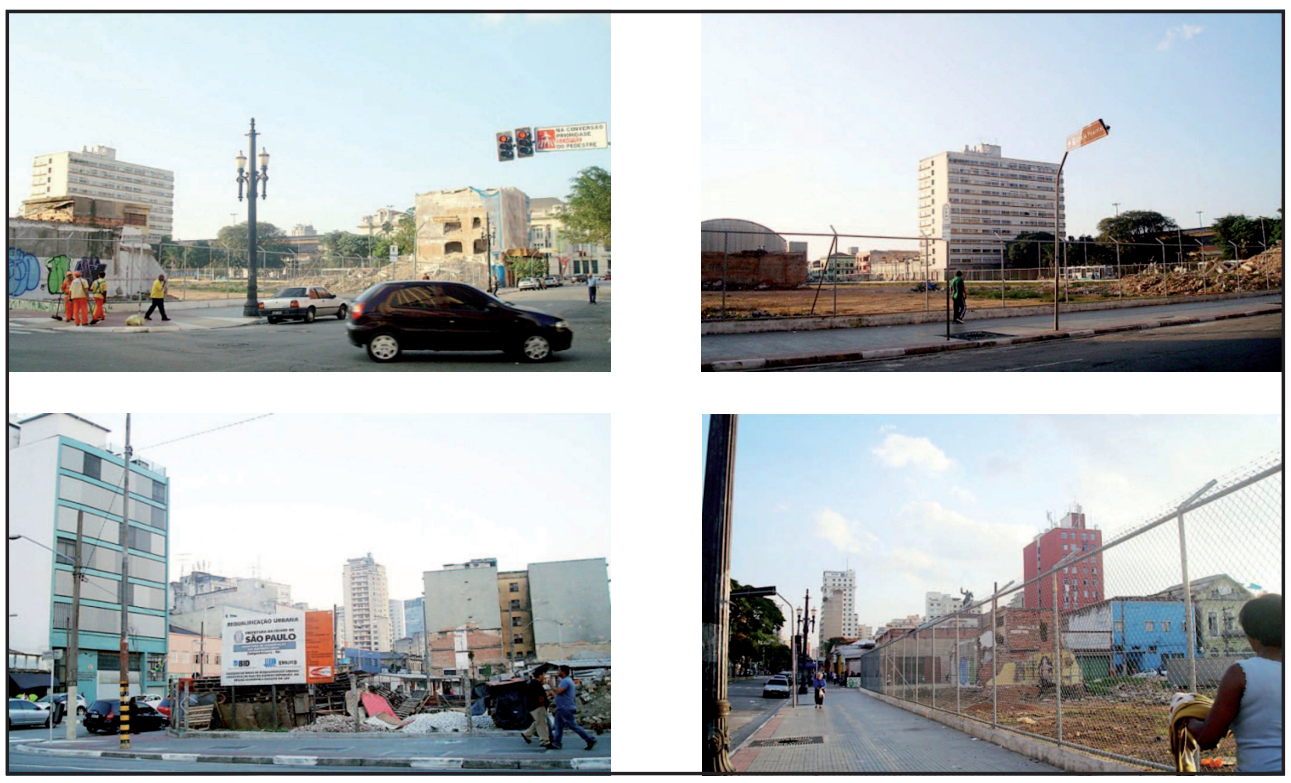

FIGURA 1 - Quatro imagens das demolições realizadas este ano na área da Luz, tomadas da Av. Duque de Caxias, uma das vias que definem o perímetro do Projeto Nova Luz. Fonte: elaboração própria, 2011. 
ra, e incluídas no perímetro abrangido pela Lei 14.096/05, que propóe incentivos fiscais para novos investimentos na área mediante a emissão de Certificados de Incentivo ao Desenvolvimento (CID) ou redução de IPTU e ISS, entre outros, com objetivo de promover a reurbanizaçáo e o incremento de usos habitacionais, de serviços e atividades ligadas à cultura e tecnologia.[3]

As demolições se iniciaram em 2007, em duas quadras, como ato simbólico do poder público, demarcando com ação direta a intençáo de melhorar a área, diante do impasse gerado após o primeiro processo de consulta pública a empresas interessadas em participar do projeto, por meio de edital lançado em 2005 e retirado no final de 2006 do site da prefeitura, em que houve a manifestação de interesse por parte de vinte empresas. Ao final desta consulta a área recebeu recursos em torno de $\mathrm{R} \$$ 3,6 milhôes, captados pela iniciativa privada, por meio da Operação Urbana Centro, destinados principalmente para as desapropriaçôes, ou seja, possibilitando que as primeiras intervençôes pudessem partir do poder público. As desapropriações e demolições das quadras têm como objetivo a construção dos edifícios sedes da Subprefeitura, da Prodam e de outras unidades da administração pública. (AVC, 2006: 29)

Náo obstante, mais recentemente, com intuito de romper a resistência de parte dos empreendedores imobiliários em investir na área,[4] a prefeitura aprova, em 2009, um instrumento de parceria público-privada, a Lei de Concessão Urbanística e sua aplicação na área declarada de utilidade pública dentro do perímetro do Projeto Nova Luz (Leis 14.917 e 14.918/2009). A lei, baseada nos termos do art. 239 da Lei do Plano Diretor Estratégico da Cidade, permite que o poder público conceda, por meio de licitação, o direito de desapropriação de uma área urbana à iniciativa privada, ou seja, a empresas ou consórcios privados, cujo interesse em investir supostamente estaria na valorização imobiliária e recuperação do investimento a partir da venda dos novos imóveis construídos, além dos já citados benefícios de isençôes fiscais, e possíveis repasses de verbas captadas na Operação Urbana Centro, conforme já foi apontado. O projeto, que está sendo desenvolvido pela prefeitura em parceria com o consórcio formado pela Concremat Engenharia, Cia City, Aecom e Fundação Getúlio Vargas, deverá ter licitação em julho deste ano. As empresas vencedoras terão o direito de vender e alugar os imóveis desapropriados por um período de 20 anos. (GRANJEIA, 2011)

Apesar da polêmica causada pelo projeto, e consoante com as iniciativas da prefeitura, o governo do estado, neste ano empreendeu a demolição da quadra onde se situava o edifício da antiga Estação Rodoviária de São Paulo, que funcionou como tal de 1961 até 1982, em frente à Estação Julio Prestes, e que, desde que as atividades foram transferidas para o Terminal Rodoviário do Tietê, passou a abrigar um shopping popular de confecções. A demolição foi iniciada após a desapropriação do prédio pelo valor de $\mathrm{R} \$ 34$ milhóes, prevista dentro do programa Pólo Luz, (TAMOTO, 2006) e teve a finalidade de abrir espaço para a construção do Teatro da Dança, com projeto do escritório suíço Herzog \& De Meuron (ESTADÃO, 2010) denominado Complexo Cultural Luz, que prevê em seu programa três teatros, escola de dança, salas de ensaios, biblioteca, auditório, café, loja, praça de convivência e estacionamento para mil veículos.

Encontra-se em curso na área da Luz em São Paulo, portanto, a implementação de uma política urbana ao avesso - sem plano ou projeto, porém
3 - "Prefeitura decide desapropriar "Cracolândia" Folhaonline, 9/9/2005.

4 - Ver argumentos de representantes da iniciativa privada descritos mais adiante. 
5 - Segundo nota geral divulgada pela Emurb (Empresa Municipal de Urbanização) à imprensa em novembro de 2002: "A Comissão Executiva da Operação Urbana Centro aprovou a liberação de cerca de $\mathrm{R} \$ 4,1$ milhões para a desapropriação de imóveis para projetos de moradia e revitalização na área da Nova Luz e da futura Praça das Artes, no Vale do Anhangabaú. Os recursos da Operação Urbana são provenientes da concessão de potencial construtivo maior do que o previsto, em troca do pagamento de valor a ser empregado pelo Município em benfeitorias na própria região. Os projetos são da Empresa Municipal de Urbanização (EMURB). Na Nova Luz, serão desapropriados nove terrenos na Rua dos Gusmões, entre as Ruas Andradas e Triunfo, num total de $2.523 \mathrm{~m}^{2}$. As áreas serão utilizadas para a construção de 199 unidades de habitação de interesse social (HIS), em obras que serão executadas numa parceria da Prefeitura com a CDHU e a Caixa Econômica Federal, via Programa de Arrendamento Residencial (PAR). A Comissão deu ainda o passo inicial para a futura Praça das Artes - projeto em parceria com a Secretaria Municipal da Cultura de revitalização do quarteirão que abrange a rua Formosa, a lateral da praça Ramos de Azevedo, a rua Conselheiro Crispiniano e a avenida São João. Foi aprovada a compra de um lote, na Avenida São João, vizinha ao Conservatório Dramático e Musical, que servirá de anexo ao Theatro Municipal. O plano para o quarteirão é criar uma área voltada para o lazer e cultura, com a transferên- com modelo de gestão já definido por meio de parcerias público-privadas, em áreas de intervenção que serão em breve licitadas, promovida pela atual gestão e prorrogada, ao que parece, até a próxima, dada a dimensão das intervençóes propostas pelo Estado e pela Prefeitura simultaneamente.

É importante ressaltar que, embora o poder público esteja explicitando sua intenção em favorecer os investimentos na área, por meio da flexibilização de índices construtivos da Operação Urbana (de 4 até 6 vezes sobre a área do lote), [5] de aplicação dos recursos do BID (Banco Interamericano de Desenvolvimento), advindos de financiamentos a programas de reabilitação de áreas centrais e aprovando um instrumento jurídico que permita aos investidores a autonomia de negociação para a desapropriação dos imóveis privados na área, muitos setores ainda manifestam reticências a este projeto. Em debate realizado pela Associação Viva o Centro, em maio de 2006, alguns dos argumentos enumerados pelos representantes da iniciativa privada foram enfáticos sobre esta questão:

(...) o incentivo fiscal é muito interessante, mas o investidor sempre vai olhar para a regiáo em função do que já existe e do que já foi desenvolvido. Então, corre-se o risco de lançar o projeto e, eventualmente, náo conseguir atrair os investidores privados que se gostaria de atrair.

(...) como fica a situação do investidor privado, em função de uma eventual discussão do valor da indenizaçáo que se arraste por anos e anos? Sabemos que este risco diminui bastante em função do pagamento de indenização prévia, em dinheiro, mas o risco ainda existe.

(...) a concessão está sendo pensada para 30 anos. Mas a questáo é: em 30 anos o investidor conseguirá amortizar os recursos gastos e ter uma margem satisfatória de rentabilidade? (AVC, 2006: 42)

Ou ainda:

Com relação ao empreendedor, a dúvida fica por conta da livre negociaçáo. A livre negociação esbarra na pulverização da propriedade e pode afugentar os investimentos uma vez que a compra pode levar anos até se encontrar todos os herdeiros. Eu, particularmente, mudaria a questão de livre negociação para a desapropriação de fato. Acho que isso ajudaria, e muito, a velocidade de qualquer tomada de decisáo por parte da iniciativa privada, fator a meu ver, crucial para o sucesso da operação. (AVC, 2006: 48)

Outros argumentos levantados ainda foram a ausência de vagas de estacionamento, mesmo considerando a grande oferta de transporte público na área, a característica das plantas dos edifícios existentes na área declarada de utilidade pública, uma vez que as novas empresas demandam plantas horizontalizadas com áreas entre 5000 a $6000 \mathrm{~m}^{2}$ e não edifícios com vários andares com áreas restritas e, por último, o próprio valor dos imóveis no centro, já que 
os mais antigos possuem grande taxa de ocupação e alto índice de aproveitamento dos lotes, o que faz com que um terreno de $200 \mathrm{~m}^{2}$ tenha até $1.200 \mathrm{~m}^{2}$ de área construída, tornando onerosa a desapropriaçáo de vários lotes para uma construção com novo padrão de ocupação. (AVC,2006: 14)

A ausência de projeto ou plano para área como um todo revela uma postura que não foi inaugurada nesta última gestão, mas vem de um longo processo que consolidou uma forma de compreender e intervir pontualmente sobre a cidade e sobre o centro, através de projetos em perímetros circunscritos, alguns bastante arbitrários, constituídos para atender a imperativos administrativos e outros decorrentes das próprias dificuldades topográficas, limitados por acidentes geográficos ou por terrenos vazios remanescentes de intervenções anteriores. A abrangência dos perímetros de áreas centrais, centros históricos, centros expandidos, como aponta Feldman (2003: 39) "encolhe e se dilata como se fosse um líquido ou gás." Como decorrência, também os perímetros adotados em planos, programas e projetos para a área se dilatam e contraem conforme objetivos específicos, que têm mais a ver com o resultado do empreendimento ou a parcela da populaçáo a que estão dirigidos do que como resultado de uma compreensão total e real da área de intervenção.

Do ponto de vista histórico, é possível apontar alguns fatores que contribuíram para uma visão setorizada da área central, já que a ocupação e, mais tarde a apropriação das áreas centrais se deu de forma distinta e paulatina, seja do ponto de vista social, funcional ou construtivo, sendo um fator importante a constituição geográfica bastante acidentada da área, aproveitando as "colinas tabulares" entre os vales dos rios que confinavam o núcleo inicial da cidade (Anhangabaú e Tamanduateí), únicas alternativas de ocupação contínua do tecido urbano.[6] Conforme nos apresenta Müller (1958: 146), o perfil topográfico da área acabou por determinar as diversas fases de expansão da centralidade paulistana. Cada uma das fases representou a superação de obstáculos oferecidos pelo sítio e a integração entre as cotas mais altas, mais ou menos isoladas, gerando a paisagem característica do centro paulistano formada por viadutos e ladeiras,[7] possibilitando mais tarde o desenvolvimento de eixos de ligação e formação de novos bairros na chamada coroa central. [Ver Fig. 2]

Assim, como o processo de expansão do centro se iniciou apenas na segunda metade do século XIX, durante muito tempo as áreas envoltórias seriam depositárias de todos os usos próprios de áreas periféricas. Na proximidade do Jardim Botânico da Luz, inaugurado em 1825, lugar de recreio dos paulistanos nos finais de semana, localizavam-se os cemitérios da Ordem Terceira do Carmo e dos Protestantes, o Mosteiro da Luz, o Presídio Tiradentes, o Quartel e o Hospital da Força Pública e a Usina Elétrica da Luz. (CADERNOS CIDADE DE SÃO PAULO, 1994)

O Campo da Luz, que hoje corresponde à Avenida Tiradentes, era um dos maiores espaços abertos de que dispunha a Imperial Cidade de São Paulo, uma área para uso público, para a qual se voltavam chácaras da aristocracia paulistana, implantadas de maneira a manter certa distância entre si, até o final do século XIX. Já era um local de comércio, onde se realizavam feiras e corridas de cavalo. Também a Ermida da Luz atraía a população para longos passeios. (CESAR, FRANCO \& BRUNA, 1977: 75) Náo obstante, o abandono das margens do Rio Tamanduateí, próximo ao encontro com o Tietê era um fator de depreciação da área por sofrer alagamentos frequentes. cia da Escola Municipal de Música, Balé da Cidade, Escola de Bailado e criação de um complexo de cinemas no Cine Marrocos." Disponível em: http://www. vivaocentro.org.br/noticias/ arquivo/101106_a_infonline.htm . Acesso em: 22/04/2011.

\section{6 - Segundo Müller} (1958:136): "Na verdade, a colina histórica constituía um recinto quase fechado pela natureza, em virtude das escarpas abruptas que a separavam dos rios Anhangabaú e Tamanduateí. A única saída fácil encontrava-se no estreito pedúnculo que, para o Sul, se encaminha na direção do Espigão Central, onde veio a instalar-se a Avenida Paulista; aproveitou-a a Rua da Liberdade, embora sem oferecer motivos de atração para o Centro, que ali só poderia tomar um aspecto linear. Para Leste, a ampla várzea do Tamanduateí constituía, como ainda hoje, um obstáculo à expansão. Para Oeste, as colinas tabulares da margem esquerda do Anhangabaú apareciam como um permanente foco de atração, ainda mais porque novos e formosos bairros nela se fixaram, mais além: mas havia um vale a transpor e, sobretudo, as águas do Anhangabaú."

7 - O primeiro viaduto construído foi o do Chá, em 1879. O segundo foi o Viaduto Santa Ifigênia (1913), seguido pelo Viaduto Boa Vista. Mais tarde, na gestão de Prestes Maia, entre as décadas de 40 e 50, foram construídos mais cinco: o Dona Paulina, o Nove de Julho, o Jacareí, o Major Quedinho e o Martinho Prado (MÜLLER, 1958:156). 


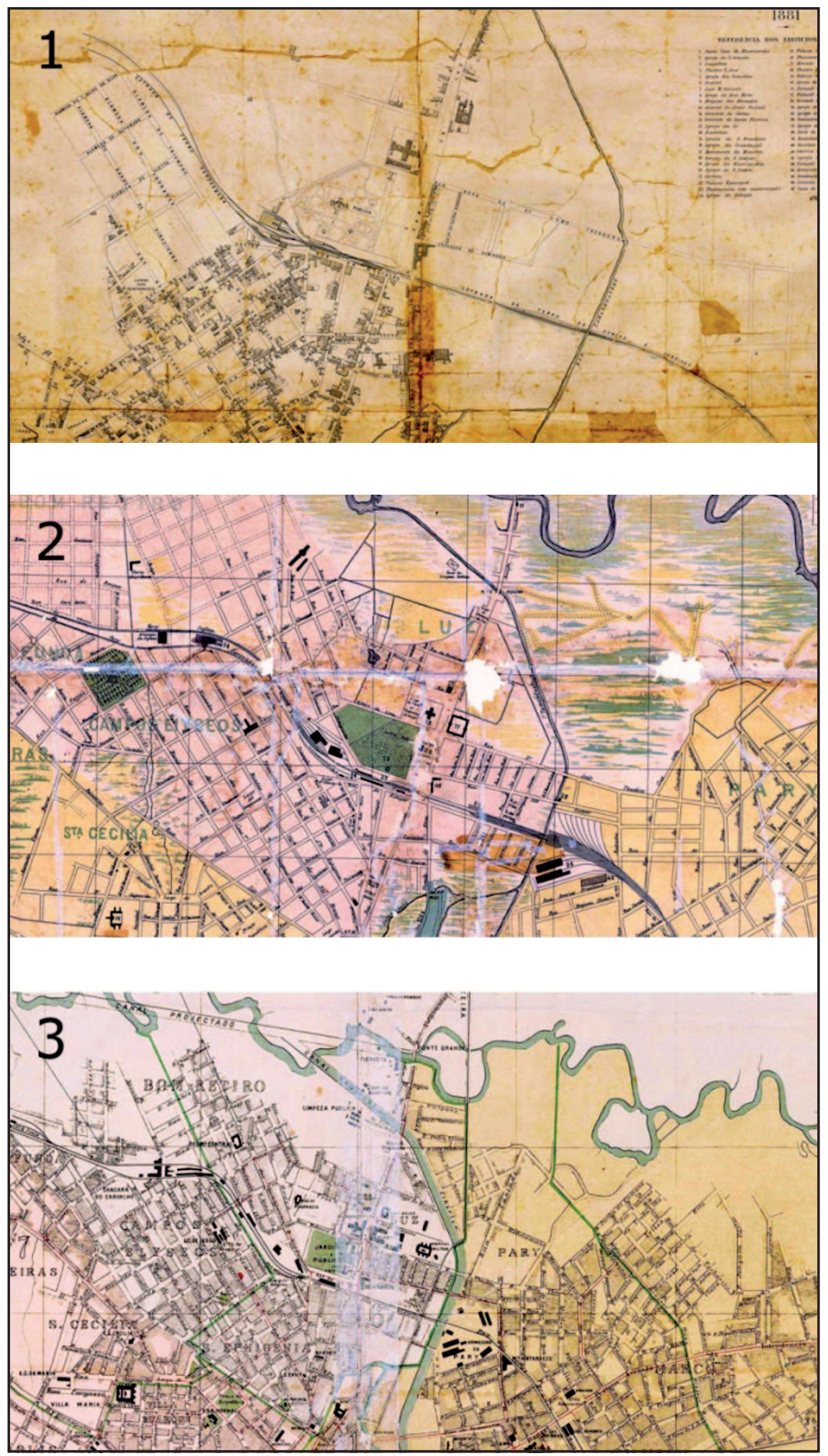

FIGURA 2 - Nesta sequência de mapas elaborados a partir dos mapas históricos da Cidade de São Paulo, é possível ver o avanço da ocupação da área da Luz. No primeiro, de 1881, é possível constatar que para além dos trilhos havia apenas o Jardim e o Campo da Luz, a Casa de Correção e o Convento da Luz. No segundo, de 1895, já se pode ver o arruamento do bairro do Bom Retiro e do Pari, além da plena ocupação do bairro de Campos Elíseos e, no terceiro, aparece já concluída a retificação do Rio Tamanduateí que possibilitou a construção dos armazéns do Pari, o Quartel, o Hospital Militar e o Seminário Episcopal. Fonte: Elaboração própria sobre Mapas da Cidade de São Paulo. Coleção do IV Centenário, 1954. Disponível em: http://sempla.prefeitura.sp.gov.br/historico/1872.php, acesso em 20/04/2011. 
Basta caminhar pela Avenida Tiradentes, com suas fileiras de árvores e dupla faixa de tráfego, marginadas por palacetes, para a gente se sentir em Paris. Mas basta aproximar-se da região do Tietê -o

"East End" de São Paulo - e você estará nas docas de Lisboa ou do Porto. [8]

Domville-Fife (1909)

Cada desdobramento de perímetro do centro, portanto, correspondeu a uma nova conquista de território, vencendo obstáculos topográficos e geográficos (várzeas e cursos d'água). Porém, um dos elementos que vai marcar a definição do perímetro central da cidade é a construção da linha férrea. A localização da principal estação ao norte do centro transformou esta área em uma fronteira para os bairros mais afastados e também definiu o desenho da coroa de bairros industriais e operários ao redor do centro. (CARVALHO, SCHICCHI, 2006) Periferia que permaneceu por muitos anos, e que nenhum projeto ou plano conseguiu reverter até período bem recente.

A construção da Estação da Luz (1900), por outro lado, foi responsável pelos primeiros surtos de urbanização para a área, principalmente por ter sido implantada concomitantemente à primeira linha de bondes da cidade ligando o Largo da Sé à estação. A localização de outra estação, a da linha Sorocabana (1929), consolidaria a função de circulação e passagem da região ao longo do século XX, assim como a expansão das atividades comerciais, industriais e a localização de armazéns e bairros operários, margeando os trilhos das ferrovias e reforçando o caráter excêntrico da área.

Em quase todas as ruas do centro e dos arrabaldes são encontradas magníficas casas; porém surpreenderam-me sobretudo as ruas Aurora, Visconde do Rio Branco (ex-rua dos Bambus), Florêncio de Abreu, Alegre, diversas dos Campos Eliseos e do Bom Retiro, todas elas em Santa Ifigênia.

O Bom Retiro é, por assim dizer, exclusivamente habitado por familias de operários, que compreendem uns 4 mil individuos... É de lastimar que não se tenham melhor preparado os terrenos do Bom Retiro para evitar que as águas pluviais fiquem retidas em alguns lugares e também podia ter havido melhor direção no alinhamento de algumas construçóes. (...) as ruas da Estação, Episcopal e outras vão ser igualmente prolongadas, atravessando a várzea para facilitar as comunicaçóes com o distrito do Brás. Ali vão ser construídos os novos armazéns da São Paulo Railway Co.(...)[9] Henrique Raffard (1890)

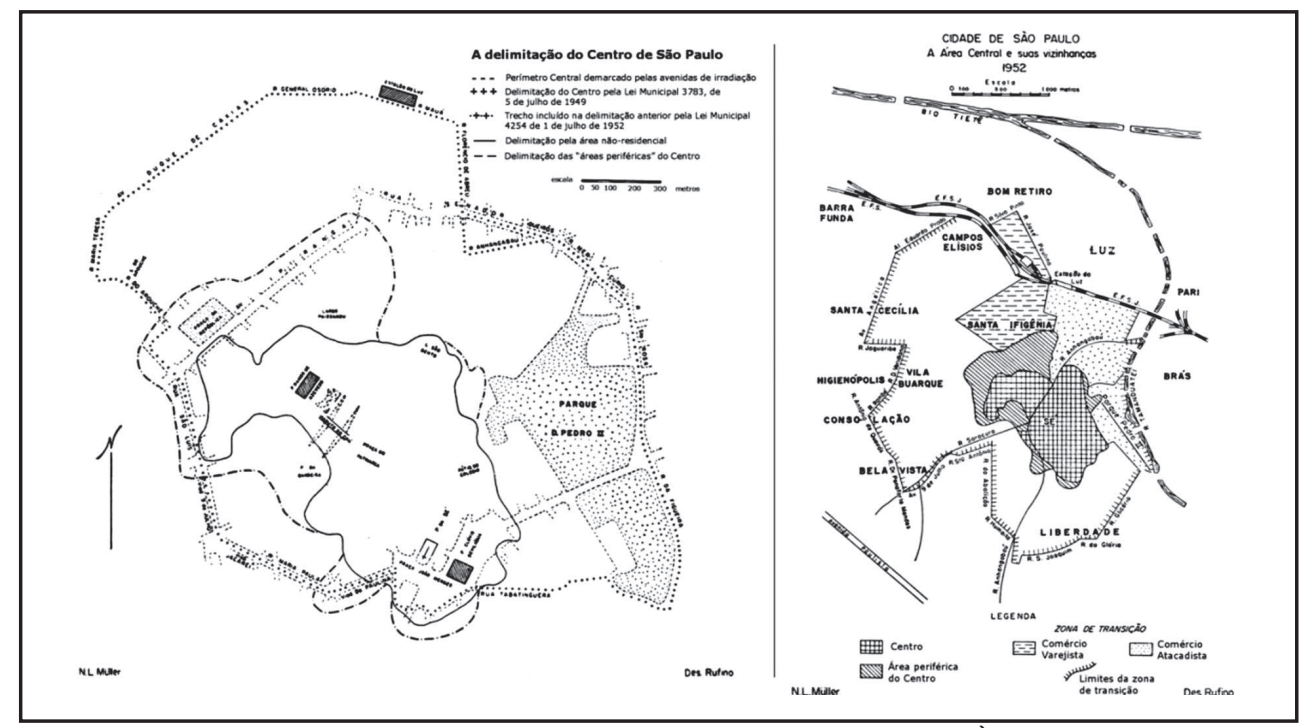

FIGURA 3-Dois mapas publicados no estudo sobre a área central de N.L.Müller. À esquerda, a autora apresenta o mapa docentro deSão Paulo eaponta possíveis critérios parasua delimitação(p.123). Àdireita, vemosolimitedocentrodacidadecomsuaáreaperiféricaeazonadetransição(p.176). Fonte:MÜLLER,1958.
8 - "São Paulo classifica-se como segunda cidade do Brasil." (BRUNO, 1981:148)

9 - "Um centro industrial cada dia mais importante." (BRUNO, 1981: 104) 
Desta forma, a área da Luz, em meados da década de 1950, em termos funcionais, já era apontada como uma zona de transiçáo do centro, caracterizada pela penetração da função comercial em bairros anteriormente exclusivamente residenciais como Santa Ifigênia e Campos Elíseos, além dos bairros limítrofes de Santa Cecília e Bom Retiro. Segundo Müller (1958: 175), tais bairros formavam uma zona que "não se classificava entre os bairros da cidade, onde as residências apareciam entremeadas por pequenas lojas, oficinas diversas, e, como elemento bastante característico dessas áreas, casas de 'rendez-vous' e pensões suspeitas." [Ver Fig. 3]

Entre outras características das áreas de transição, apontadas neste momento, algumas poderiam perfeitamente definir aspectos presentes ainda hoje na paisagem da Luz (MÜLLER,1958: 178-179):

De fato, à espera de circunstâncias mais favoráveis e ùnicamente preocupados em obter melhores rendimentos, muitos proprietários deixam os prédios em lamentável abandono, sem se preocuparem com sua conservação, o que pode ser constatado em suas fachadas clamando por nova pintura, nas vidraças quebradas, nos interiores, incrìvelmente maltratados. Chegado o momento propício, tais prédios ver-se-ão demolidos e serão substituídos por novos edifícios, geralmente arranha-céus, que conterão apartamentos e cujo pavimento térreo será reservado para lojas comerciais.

(...) essa deterioração material constitui um dos característicos das cidades novas de tipo americano, assim como a existência da própria zona de transição (...) o baixo meretrício achava-se concentrado nessa zona de transição, numas poucas ruas do Bom Retiro. Todavia, em virtude de decisão do Govêrno do Estado, foram evacuadas as casas de tolerância existentes e, consequentemente, dispersadas as infelizes que ali viviam; tal medida, porém, não conseguiu resolver o problema e teve como consequência a localização das meretrizes em pontos esparsos, sobretudo no bairro dos Campos Elísios, o que, sob certo aspecto, veio agravar o problema, uma vez que passaram elas a viver em áreas ainda residenciais, em inevitável contato com as famílias que nelas habitam. [Grifo da autora]

Já em meados dos anos 1970, a função de circulação e transportes era apontada como preponderante nesta área, uma vez que se constituiu em ligação entre o sul e o norte da cidade, com a formaçáo dos eixos representados pelas Avenidas Tiradentes, Cruzeiro do Sul e do Estado. (CESAR, FRANCO \& BRUNA, 1977: 92) O fato de ser atravessada por esses grandes eixos rodoviários acabou contribuindo também para a degradação da área, que além dos aspectos ambientais negativos (ruído, fumaça e poeira), também foram responsáveis pela fragmentação dos tecidos urbanos e isolamento dos bairros intersticiais, como os do Pari e Brás a Leste e os do Bom Retiro e Campos Elíseos, a oeste, fato que se somou aos vazios produzidos ao longo dos eixos ferroviários. A construção da 
Rodoviária, o aumento de linhas de ônibus interurbanos que atravessavam a Luz em direção à Via Dutra e Fernão Dias, nos anos 1960, consolidariam o caráter metropolitano da área, aspecto que seria reforçado após a inauguração das estaçôes do Metrô nos anos 1980. Este quadro é o que se apresentava na ocasião em que foi realizado o primeiro diagnóstico e proposta para a renovação urbana da área da Luz, em 1977.[10]

Ao mesmo tempo, decorrente desta definição funcional de circulação, aí remanesceram as áreas ocupadas desde os primórdios por diversos usos característicos de arrabaldes, ocupando grandes quadras, ou conjunto de quadras, tais como o Jardim da Luz, o Mosteiro da Luz (1774), transformado em Museu de Arte Sacra, a Pinacoteca do Estado (1897) (anteriormente, até meados dos anos 1980, ocupada também pela Escola de Belas Artes), o Solar do Marquês de Três Rios, a Escola Politécnica ou Faculdade de Tecnologia de São Paulo (1893), o Quartel da Força Pública (1892) ou Quartel da Luz, o conjunto de edifícios da Praça Coronel Fernando Prestes, a Casa de Correção (1852) de cuja construção demolida em 1972 só restou o Arco de Entrada, o Seminário Episcopal ou Igreja de São Cristóvão (1853), a Usina Termoelétrica (1892), outra construção demolida em 1985 da qual só restou uma chaminé (PROGRAMA MONUMENTA/ BID, 2001), assim como os hotéis Conde de Queluz e Federal Paulista (início do século XX), equipamentos presentes até hoje e cujos usos foram se transformando ao longo do tempo.

Comecemos pela face norte. Quem, da Estação da Luz, descesse pelo primitivo caminho do Guaré, antiga estrada para Atibaia, mais tarde rua Comércio da Luz e atual Avenida Tiradentes, notaria de lado a lado, até a Ponde Grande, insignificante número de casas; em geral, residências senhoriais, um tanto distantes umas das outras dentro de grandes chácaras. Destacavam-se, por sua imponência, os edifícios do Seminário Episcopal, do Convento da Luz e o da residência do comendador Fidêncio Prates, que bem posteriormente nela instalou-se a Escola Politécnica. A Casa da Correção já existia desde 1850, bem como o romântico Jardim Público, com seus característicos encantos, dentre os quais o célebre "canudo do João Teodoro", simples torre de tijolos, de uns quarenta metros, encimada de mirante de onde se descortinava belo panorama circular de grande raio, abrangendo toda a cidade.[11]

Everardo Valim Pereira de Souza (1886-1991)

Com esta característica de transformação dos usos dos edifícios, outra vocação seria apontada para a recuperação da área. Retomando a tendência verificada já no final da década de 1970, o Governo do Estado promoveria um novo estudo para a área, em 1984, o Projeto Luz Cultural, cujo principal objetivo era a integração dos espaços públicos e institucionais da área, reforçando seu caráter de pólo cultural. Nesta mesma direção, em 1998, o Projeto Luz, desenvolvido dentro do Programa de Reabilitação do Patrimônio Cultural do IPHAN (Instituto do Patrimônio Histórico e Artístico Nacional), com recursos do BID e coordenado pelo DPH (Departamento do Patrimônio Histórico) da prefeitura de São Paulo, também potencializaria as atividades culturais, investindo num circuito de lazer e turismo, propondo várias melhorias para a área, desde equipamentos para praças até a implantação de um camelódromo, visando ordenar o comércio informal do entorno das estaçóes. No final da década de 1990, vários estudos sucessivos seriam realizados, promovidos pela Associação Viva o Centro (2000), entre eles o "Sáo Paulo Centro - Uma nova abordagem", o "São Paulo Centro" e, por ocasião da implantação do Complexo Cultural Júlio Prestes (1999), o "Pólo Cultural Luz".
10 - Trabalho intitulado "Área da Luz. Renovação urbana em São Paulo", realizado por equipe técnica do escritório Rino Levi Arquitetos Associados por solicitação da COGEP (Coordenadoria Geral de Planejamento, atual SEMPLA) tendo em vista a regulamentação das "Zonas Especiais" propostas na Lei de Zoneamento, nas quais a área da Luz se enquadrava.

11 - "Triste e monótona a vida social da cidade". (BRUNO, 1958: 100) 


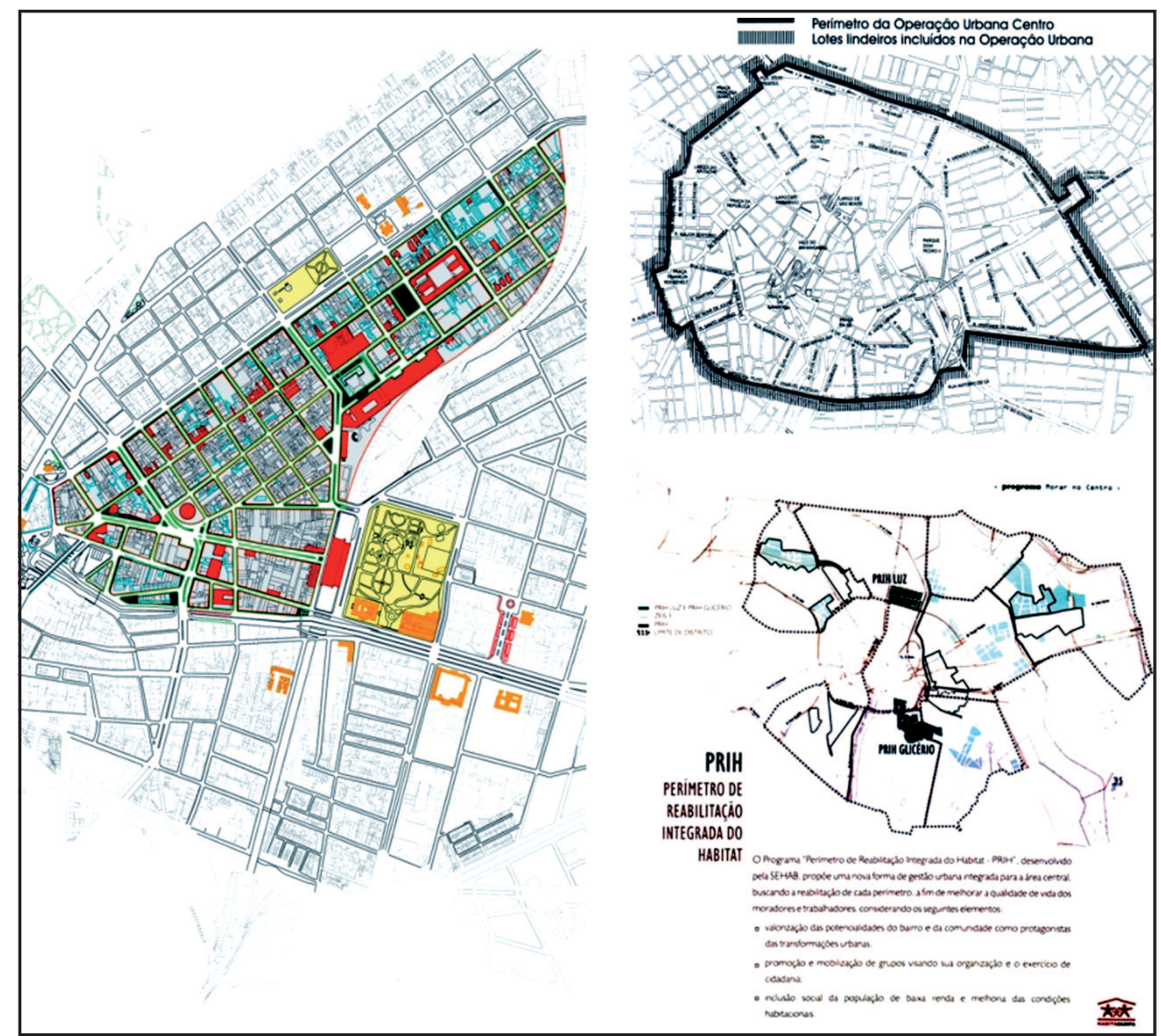

FiguRA 4 - Três delimitações de perímetro referentes à área. À esquerda, o perímetro do Programa Pólo Luz-Santa Ifigênia, à direita superior, o perímetro de intervenção da Operação Urbana Centro e, à direita inferior, o perímetro de atuação do PRI - LUZ (Perímetro de Reabilitação Integrada do Habitat), proposto na gestão Marta Suplicy. Fonte: Projeto Pólo Luz, Edital da Operação Urbana Centro e Programa Morar no Centro (HabitaSampa). Disponíveis em: http://www.vivaocentro.org.br/biblioteca/index.htm e http://www.prefeitura.sp.gov. br/cidade/secretarias/desenvolvimento_urbano/novas_operacoes_urbanas/,respectivamente.

(MEYER; IZZO, 2000: 129-146) Seguindo esta mesma linha de valorização dos edifícios públicos, o Programa Monumenta/BID inicia sua atuação na cidade a partir da definição de um conjunto de edifícios históricos na área da Luz, pois, conforme já foi descrito, esta é a região que mais concentra equipamentos culturais e edifícios remanescentes de valor histórico e artístico, única a atender aos critérios de candidatura definidos pelo IPHAN. [Ver Fig. 4]

Para cada um destes projetos e estudos, assim como para as áreas consideradas pelos planos diretores e concursos de idéias realizados, houve um perímetro diferente definido. Em alguns, a área da Luz era parte da área central, em outros, o traçado da ferrovia coincide com o limite da área considerada, e por fim, o bairro da Luz não conforma oficialmente um território autônomo, ora considerado como parte da Subprefeitura Sé, ora incluído no distrito de Bom Retiro. [Ver Fig. 5]

- Campo, caminho, pouso, chácaras de arrabalde...

- Jardim Botânico, passeio público, parque...

- Ermida, convento, igreja, seminário...

- Casa de Correção, Cadeia Pública, Quartel...

- Entroncamento ferroviário, rodoviária, eixos viários...

- Museus, pinacoteca, sala de concertos... 
- Escola técnicas, Faculdades, Edifícios institucionais...

- Comércio especializado, atacadista, popular...

- Bairro aristocrático, bairro típico, bairro popular, vila operária...

- Galpóes, depósitos, fábricas, garagens...

A diversidade de usos não conseguiu configurar um caráter de centralidade na área da Luz, pois estes jamais convergiram. Ao contrário, os usos convivem lado a lado sem se integrarem. Os bairros de comércio especializado possuem uma dinâmica própria e seus próprios transeuntes, funcionários, consumidores, assim como os que se destinam aos museus e sala de concertos parecem ignorar a pulsação dos que passam pela estação dirigindo-se a outras cidades. Os inúmeros edifícios institucionais e educacionais presentes representam outra lógica de circulação, assim como o percurso dos moradores dos bairros envoltórios, os lugares escolhidos pela população em condição de rua, pelos usuários dispersos nos

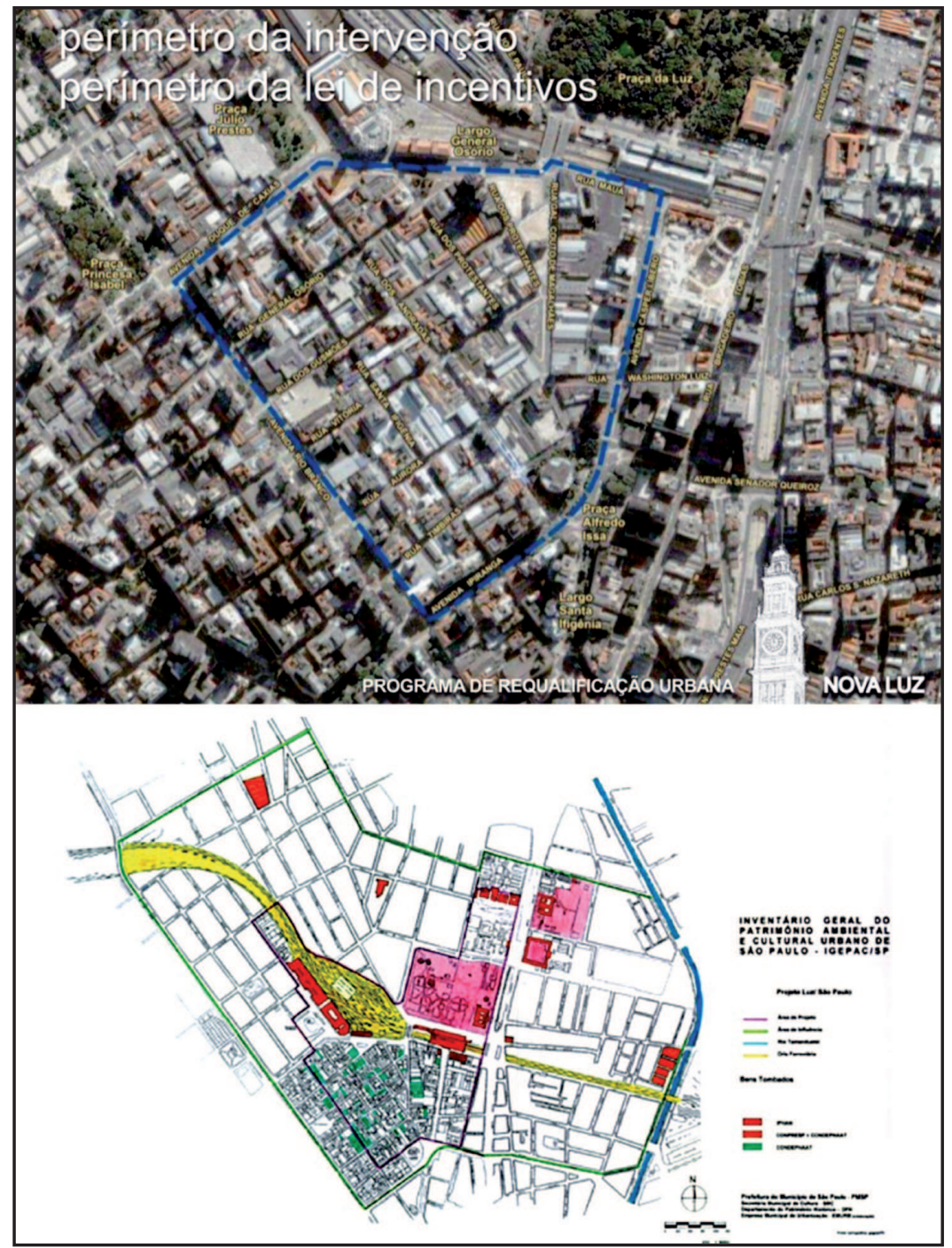

FIGURA 5 - Mais dois perímetros de intervenção distintos na área da Luz: na imagem superior, o perímetro de Intervenção do Projeto Nova Luz e na imagem inferior, delineado na cor roxa, o Perímetro de Intervenção do Programa Monumenta/BID - Luz. É possível constatar que o perímetro do Monumenta incorpora a área do Projeto Nova Luz em sua área de influência do Programa, delimitada na cor verde e apenas assinala os edifícios tombados dentro da área de projeto. Fontes: Nova Luz - Programa de Requalificação Urbana, 2009 e Programa Monumenta/BID, Ministério da Cultura, 2001, respectivamente. 
espaços públicos, emergindo em massa nas saídas das estaçôes, organizados em blocos na entrada dos museus. Recordo-me da pergunta que faz Arantes (1994: 191-192) em seu relato de uma caminhada realizada pelo centro de Sáo Paulo: "qual é a natureza dessas fronteiras contraditórias?" E respondendo à própria pergunta, assim descreve o autor:

Mais do que territórios bem delimitados, esses "contextos" ou "ambientes" podem ser entendidos como zonas de contato, onde se entrecruzam moralidades contraditórias (...), aproximam-se mundos que são parte de um mesmo modo mas que, assim mesmo, encontram-se irremediavelmente apartados.

Aqui parece se configurar outra categoria de espaço, que não é propriamente um bairro (reconhecível, familiar) e também não é o centro, ou seja, um território que ainda guarda aquela característica de "zona de transiçáo" detectada no final dos anos 1950, embora hoje já consolidado. Visivelmente setorizado, cindido, ainda que possua grande acessibilidade, repleto de "lugares sociais efêmeros" ou inóspitos, representados pelos interstícios entre grades e muros de grandes edifícios ou parques públicos, canteiros centrais de avenidas, ruas sem saídas ou confinadas pelos trilhos, sem esquinas, grandes espaços públicos de retorno e orientação do fluxo viário, sem calçadas, ou com calçadas confinadas por grades, guard rails, sem passagem ou travessia, quarteiróes murados para proteção dos trilhos ou para privacidade dos quartéis. A presença de interesses diversos e as múltiplas edificações de interesse histórico só conseguem conciliação na ausência de um desenho urbano, prevalecendo uma ostensiva profusáo de elementos que obrigam a certo tipo de conduta, uso e circulação nos espaços, que não possuem urbanidade. [Ver Figs. 6 e 7] Novamente, a exemplo de outros espaços públicos da cidade contemporânea, os espaços conformados na área da Luz, em especial:

(...) convergem para locais deste tipo e neles ganham visibilidade algumas das principais tensóes e conflitos sociais. Aí se expóe publicamente a falta de direitos de cidadania da grande maioria da população da cidade, que se identifica na incidência de assaltos, no comércio e ostensivo consumo de drogas, na construção de moradias "invisíveis", no subemprego, na mendicância e na oferta de uma vida melhor

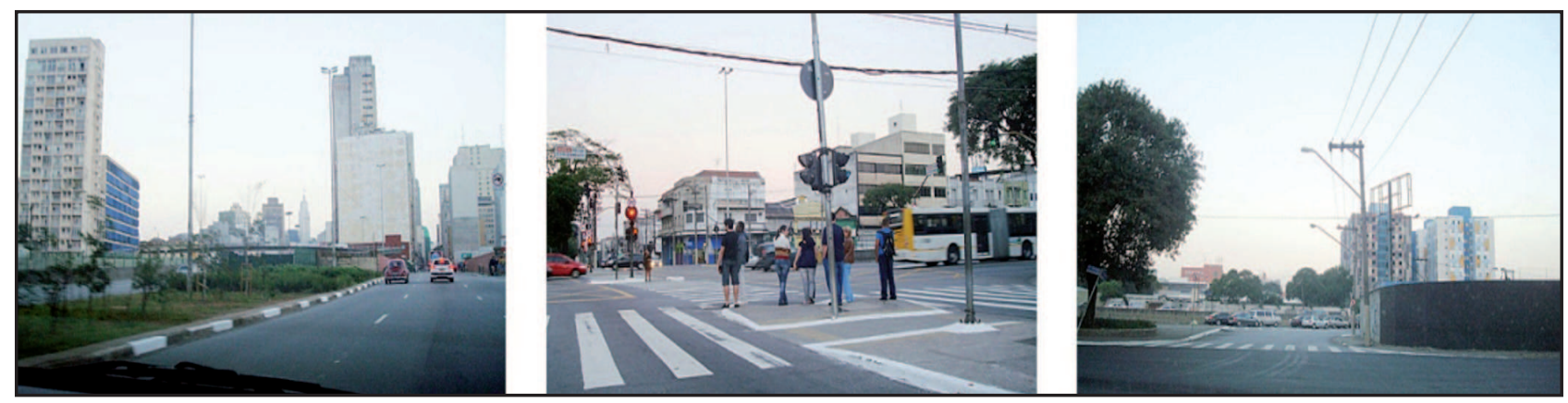

FIGURA 6 - Áreas próximas à Av. Tiradentes. É possível verificar na foto do centro, a grande distância que implica a travessia de um lado ao outro da via, onde não há calçadas nos pontos intermediários, apenas a pintura das faixas. O canteiro central, na foto à esquerda, apesar de ter uma calçada, não permite a travessia, pois tem uma cerca na extremidade oposta. À direita, a Rua Ribeiro de Lima em direção à Av. Tiradentes, onde se pode constatar a sequência de obstáculos interpostos aos pedestres. Fonte: Elaboração própria, 2011. 


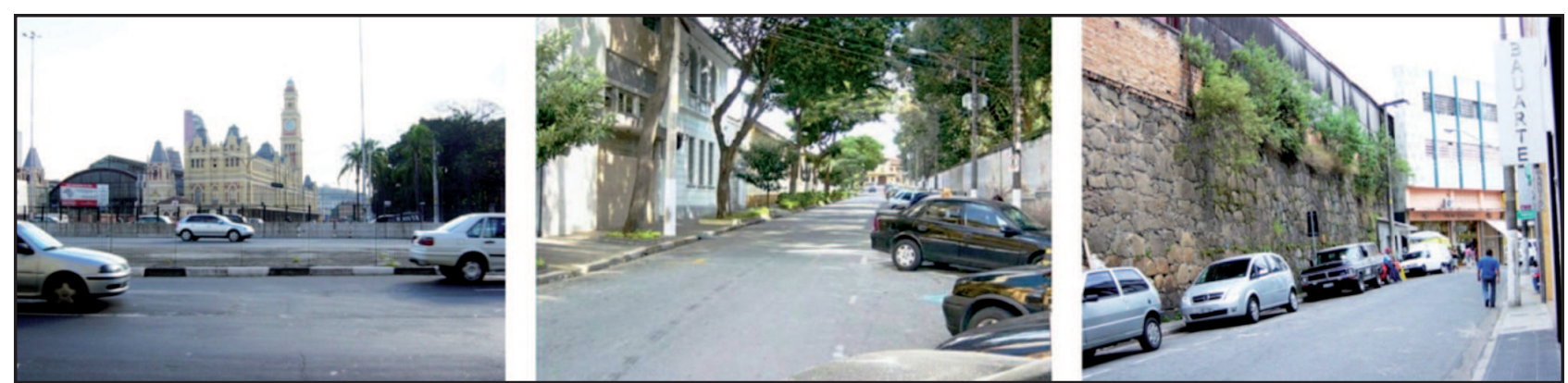

FIGURA 7- Outra sequência de fotos que mostram a falta de urbanidade na área. À esquerda, a travessia em frente à Pinacoteca e à Estação da Luzé impossível. Ao centro, vemos uma das ruas localizadas no lado leste da Av. Tiradentes, atrás da área do Quartel, praticamente murada de um dos lados. O mesmo ocorre na rua dos fundos da Estação Júlio Prestes, à direita. Fotos: Juliana Nahas de Carvalho, 2004.

através das loterias, das poções milagrosas e das pregaçóes religiosas. Ao mesmo tempo, diversas instituiçóes políticas e assistenciais trazem para este cenário a sua palavra e as suas práticas salvadoras. E aí, também, o controle social assume a forma ritualizada de policiamento ostensivo: retórica que em princípio criminaliza o habitante das ruas, classificando-o socialmente como "coisa fora de lugar", portanto simbolicamente suja e perigosa. (ARANTES, 1994: 192)

O quadrilátero formado pelas ruas General Osório, dos Protestantes, Aurora e dos Andradas, na regiáo próxima à Estação da Luz, um lugar em que circulam tanto moradores, comerciantes, prostitutas, garotos em situação de rua e transeuntes, ilustra bem o espaço liminar em que se compartilham estas regras de convivência. Não há conflito e sim uma grande indiferença entre estes diferentes mundos entrecruzados.

A partir de 1995, a ação veio de fora, com a chamada "limpeza urbana", em que caminhóes-pipas da prefeitura chegavam pela manhã e expulsavam quem estivesse dormindo em praça pública. (CAMPOS, 1999) Em seguida, em 2005, ocorreu a primeira "Operação Limpa", de muitas que se seguiriam como conduta

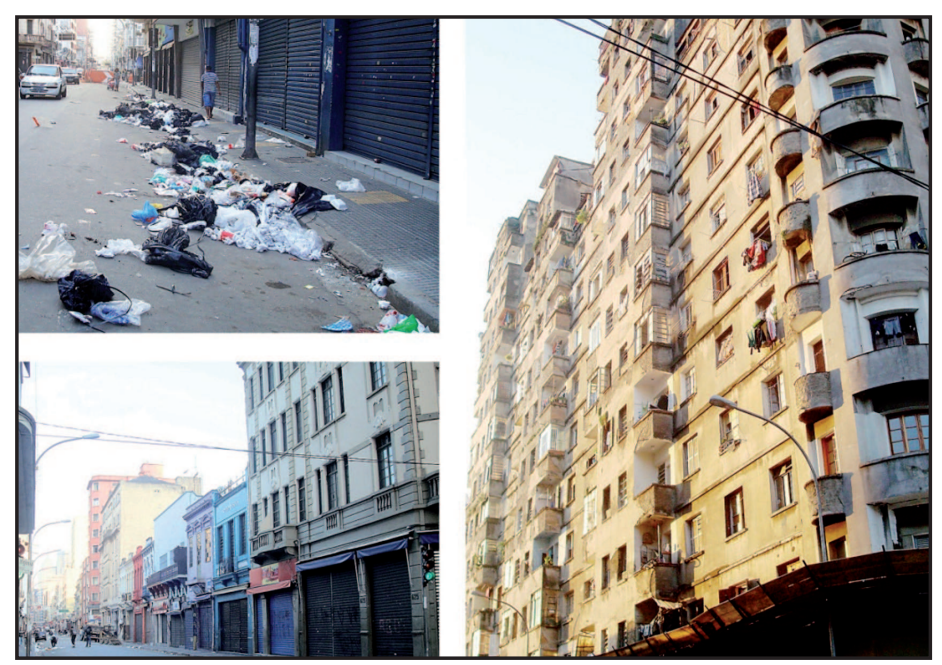

FIgURA 8 - Imagens da área de Santa Ifigênia. Acima, tomada da Rua Santa Ifigênia, num sábado à tarde, depois do horário comercial. É possível ver a falta de movimento e os sacos de lixos já vasculhados pela população em condição de rua. Abaixo, uma vista da esquina da Rua General Osório com a Rua Santa Ifigênia, outro cenário vazio, embora haja muitos moradores nos andares superiores dos edifícios, como o que é apresentado à direita, na Rua General Osório. Fonte: Elaboração própria, 2011. 
adotada pelo policiamento da área, que junto com o fechamento de estabelecimentos e prisôes de contraventores e traficantes, expulsou a população de rua e as prostitutas das áreas próximas das estações e edifícios públicos, causando uma dispersão das crianças e adolescentes para áreas próximas como Santa Cecília, Vila Buarque, Anhangabaú e Minhocão, itinerância semelhante à que ocorria na área em meados da década de 1950, como já foi relatado, e uma demonstração de pouca evoluçáo nos métodos de controle e repressão social. [Ver Fig. 8]

Sobre a imagem da área, divulgada pela mídia e reiterada pelos órgãos públicos gestores do Projeto Nova Luz, a de que “(...) a região era irradiadora de criminalidade e bloqueava a atividade econômica existente no Bom Retiro. Ou seja, a propriedade do Bom Retiro que é próspera, contrastava com as suas extremidades, a Rua dos Gusmóes, a Rua Mauá e a própria vizinhança da Subprefeitura da Sé (...)" (AVC, 2006: 11) - sendo estas as áreas onde as intervençóes do projeto Nova Luz estão propostas - o perigo é que, como afirma Lacarrieu (2007: 51), ainda que construçáo parcial, superficial e distorcida da realidade local - já que esta é multifacetada, como já apontado - toda imagem urbana tende a estabilizar-se. Segundo a autora, mesmo com ligeiras mudanças, incorporação ou eliminação de componentes, as imagens urbanas são construções que perduram quase imutáveis, com forte incidência sobre os modelos políticos urbanos, mas também nos imaginários e nas práticas sociais. Assim, as imagens urbanas acabam constituindo-se na matéria prima dos discursos e, quando legitimadas, se tornam hegemônicas nas disputas sociais. E conclui: "Suelen aspirar a definir proyectos urbanos que pretenden imponerse a la ciudadanía y trasmitiendo valores y comportamientos desde los cuales se decide qué formas de apropriación de los espacios se autorizan y qué rasgos culturales deben asumirse".

Baseada em autores como De la Torre (1998: 46) e Torres \& Ribeiro (1996), Lacarrieu aponta que, neste caso, se trata de projetar uma territorialização da imagem hegemônica do que a cidade deve ser e de como deve ser vivida, assim como dos limites entre o próprio e o alheio, entre o permitido e o proibido, o tolerável e o intolerável, o reconhecível e o inominável e, portanto, a imagem associada ao poder é prescritiva.

Imposta a territórios onde não existe um caráter próprio definido, mas uma conformação multifacetada, em que não há resistências pelo viés identitário, a memória da cidade, materializada no conceito de patrimônio é delimitada tendo como base os objetos materiais urbanos que a fortalecem para gerar discursos valorativos, ou seja, a imagem urbana intervém no "trabajo de encuadramiento de la memoria” (POLLAK, 1989:9 apud LACARRIEU, 2007: 53) que rapidamente se cristaliza no nível da patrimonialização material. Neste sentido, a imagem urbana retoma componentes chaves de um passado recente ou remoto e os reinterpreta em função de um presente-futuro. Ou não seria possível entender a frase: "Mas a declaração de que a área é de utilidade pública já deve mobilizar o mercado imobiliário da região", dita por um membro do conselho imobiliário da OAB (Ordem dos advogados do Brasil) sobre as desapropriaçóes previstas para a área do Projeto Nova Luz (FOLHA DE S. PAULO, 2005).

$\mathrm{O}$ que se pretende com o conjunto e com cada um dos projetos propostos para a área em questáo, quando não se explicita a imagem da área que se quer obter ao delimitar a intervenção, é que a imagem resulte da própria açáo intencional de recorte e seleção. Assim, as imagens urbanas organizam paisagens, que não seriam senão produtos de uma política de lugares, (DELGADO RUIZ, 
1998 apud LACARRIEU, 2007: 54) ao contrário do sentido dos lugares que emergem do conjunto de imaginários compartilhados pelos diferentes grupos sociais. Enquanto um é resultante de intercâmbios e relaçóes com os contextos sócio-históricos e políticos que se forjam, o outro é processual, ou seja, reconhece o contexto sócio-político e histórico mas também as continuidades e descontinuidades dos processos. (LACARRIEU, 2007: 55)

Como concluem Frúgoli Jr. \& Sklair, em estudo recente sobre a maneira como a populaçáo da área do projeto Nova Luz julga as intervençóes propostas (2009: 125):

Luz e Centro se entrelaçam enquanto representaçóes espaciais, embora a primeira categoria remeta claramente, como vimos, aos 'nóias' - marcados pela sua presença física nas ruas e associados simbolicamente a uma série de estigmas - sujeira, perigo, ameaça à segurança (principalmente à noite), drogas, encrenca, vergonha etc.

A mais recente proposta de intervenção denominada Nova Luz, pelo próprio nome já renuncia a qualquer traço deste presente conflituoso, complexo e resiliente, para tentar construir uma imagem da área a partir de um recorte, e impor uma renovação a partir de padrôes hegemônicos de espaços contemporâneos, com forte referência de modelos exitosos externos.

Neste sentido, volto à questão inicial aqui colocada: que formas de apropriação do bairro da Luz sáo legítimas e desejáveis, e que recortes culturais e espaciais devemos assumir para os projetos?

A importância de responder tal pergunta e motivo de toda reflexão aqui proposta é que, de acordo com o que foi divulgado na imprensa, caberá ao poder executivo municipal elaborar o projeto urbanístico, com todas as açóes, restriçóes e contrapartidas para o setor privado, portanto, a despeito de equívocos de compreensão da área, dos perímetros definidos arbitrariamente e impostos a partir de decisóes de gabinete, constitui-se uma oportunidade de atuarmos no intuito de fazer valer o desejo dos que habitam e frequentam o bairro da Luz, ou de todos nós.

\section{REFERENNCIAS BIBLIOGRÁFICAS}

ARANTES, Antonio Augusto. "A guerra dos Lugares. Sobre Fronteiras Simbólicas e Liminaridades no Espaço Urbano". In: Revista do Patrimônio Histórico e Artístico Nacional. Rio de Janeiro: IPHAN, 1994.

ASSOCIAÇÃO VIVA O CENTRO (AVC). Mesa Redonda sobre intervenções na Quadra 27 e no Pólo Luz - Santa Ifigênia. São Paulo, 10/05/2006, 57p.

BRUNO, Ernani Silva. Memória da Cidade de São Paulo. Depoimentos de Moradores e Visitantes /1553-1958. Secretaria Municipal de Cultura/Prefeitura do Município de São Paulo. Série Registros 4. São Paulo: Departamento do Patrimônio Histórico, 1981.

CADERNOS CIDADE DE SÃO PAULO. Região Tiradentes. São Paulo: Instituto Cultural Itaú, 1994.

CAMPOS, Morgana. "O mapeamento do Quadrilátero do crack". In Jornal da USP. Pesquisa, ESPECIAL/VIOLÊNCIA. DROGAS. São Paulo, 1999.

CARVALHO, Juliana Nahas Brasilino de, SCHICCHI, Maria Cristina da Silva. A "Área da Luz em São Paulo: Reabilitação de edifícios históricos versus Recupera- 
ção urbana”. In Os Urbanitas. Revista Eletrônica de Antropologia Urbana. Ano 4, Vol.4, n5. São Paulo, fevereiro de 2007. Disponível em: http://www.aguaforte. com/osurbanitas5/Carvalho\&Schicchi2007.html, Acesso em: 23/05/2011.

CESAR, Roberto de Cequeira, FRANCO, Luiz Roberto Carvalho, BRUNA, Paulo Valentino. Área da Luz. Renovação Urbana em São Paulo. Sáo Paulo: Editora Perspectiva S.A., 1977.

ESTADÃO.COM.BR/São Paulo. "Demolição de rodoviária começa a mudar a Luz”. 13/abril/2010. Disponível em: http://www.estadao.com.br/estadaodehoje/20100413/not_imp537573,0.php, acesso em: 25/05/2011.

FELDMAN, Sarah. São Paulo: "Qual Centro?" In SCHICCHI, Maria C.; BENFATTI, Dênio. Urbanismo: Dossiê São Paulo - Rio de Janeiro. Campinas: PUCCampinas/PROURB, 2003.

Folha de S. Paulo. Folhaonline. "Prefeitura decide desapropriar 'cracolândia". São Paulo, 09/09/2005. Disponível em: http://wwwl.folha.uol.com.br/folha/cotidiano/ult95u112888.shtml . Acesso em: 20/04/2011.

FRÚGOLI Jr., Heitor, SKLAIR, Jessica. "O bairro da Luz em São Paulo: questóes antropológicas sobre o fenômeno da gentrification". In Cadernos de Antropologia Social no30, p.119-136. Buenos Aires: UBA, 2009. Disponível em: http:// redalyc.uaemex.mx/src/inicio/ArtPdfRed.jsp?iCve=180913916007 . Acesso em: 20/04/2011.

GRANJEIA, Julianna."Justiça cassa liminar que suspendia projeto Nova Luz, em São Paulo”. Folha de S. Paulo. Folha.com. Caderno Cotidiano, 29/04/2011. Disponível em: http://wwwl.folha.uol.com.br/cotidiano/909301-justica-de-sp-cassaliminar-que-suspendia-projeto-nova-luz.shtml Acesso em: 29/04/2011.

LACARRIEU, Mônica. La “insoportable levedad” de lo urbano. Revista EURE (Vol. XXXIII, no99), pp.47-64. Santiago de Chile: Pontifícia Universidad Católica de Chile, agosto de 2007.

MEYER, Regina M. P., IZZO JR., Alcino. Pólo Luz. Sala São Paulo, Cultura e Urbanismo. São Paulo: Editora Terceiro Nome, 1999.

MÜLLER, Nice Lecocq. A Área Central de São Paulo. In AZEVEDO, Aroldo. A cidade de São Paulo. Vol.III, São Paulo: Companhia Nacional, 1958.

TAMOTO, Rejane."Mais R \$ 3,6 mi para revitalização da Cracolândia”. Diário do Comércio. Caderno Cidades, 29/11/2006. Disponível em: http://www.viva- 